\title{
Adsorption of Water Vapor by Bare Soil in an Olive Grove in Southern Spain
}

\author{
A. VERHOEF \\ Department of Soil Science, School of Human and Environmental Sciences, University of Reading, Reading, United Kingdom \\ A. DiAZ-ESPEJO \\ Instituto de Recursos Naturales y Agrobiologia, CSIC, Seville, Spain \\ J. R. KNIGHT \\ Department of Soil Science, School of Human and Environmental Sciences, University of Reading, Reading, United Kingdom \\ L. Villagarcía \\ Departmento de Sistemas Físicos, Químicos y Naturales, Universidad Pablo de Olavide, Seville, Spain \\ J. E. FERNÁNDEZ \\ Instituto de Recursos Naturales y Agrobiologia, CSIC, Seville, Spain
}

(Manuscript received 5 January 2006, in final form 12 June 2006)

\begin{abstract}
Data for water vapor adsorption and evaporation are presented for a bare soil (sandy loam, clay content $15 \%$ ) in a southern Spanish olive grove. Water losses and gains were measured using eight high-precision minilysimeters, placed around an olive tree, which had been irrigated until the soil reached field capacity $\left(\sim 0.22 \mathrm{~m}^{3} \mathrm{~m}^{-3}\right)$. They were subsequently left to dry for 10 days. A pair of lysimeters was situated at each of the main points of the compass (N, E, S, W), at a distance of $1 \mathrm{~m}$ (the inner set of lysimeters; ILS) and $2 \mathrm{~m}$ (the outer set of lysimeters; OLS), respectively, from the tree trunk.

Distinct periods of moisture loss (evaporation) and moisture gain (vapor adsorption) could be distinguished for each day. Vapor adsorption often started just after noon and generally lasted until the (early) evening. Values of up to $0.7 \mathrm{~mm}$ of adsorbed water per day were measured. Adsorption was generally largest for the OLS (up to $100 \%$ more on a daily basis), and increased during the dry down. This was mainly the result of lower OLS surface soil moisture contents (period-average absolute difference $\sim 0.005 \mathrm{~m}^{3} \mathrm{~m}^{-3}$ ), as illustrated using various analyses employing a set of micrometeorological equations describing the exchange of water vapor between bare soil and the atmosphere. These analyses also showed that the amount of water vapor adsorbed by soils is very sensitive to changes in atmospheric forcing and surface variables. The use of empirical equations to estimate vapor adsorption is therefore not recommended.
\end{abstract}

\section{Introduction}

A gain of water in the soil surface layer, not caused by rainfall or irrigation, can be caused by dew deposition or vapor adsorption. Dew deposition is a phenomenon recorded for most soil and climate types (Jacobs et al. 1994, 1999). It occurs during the night when dewpoint is reached, and it results in a discernable wetting of the surface (Monteith 1957).

Vapor adsorption is an important phenomenon in

Corresponding author address: Dr. Anne Verhoef, Dept. of Soil Science, School of Human and Environmental Sciences, P.O. Box 233, Whiteknights, University of Reading, Reading RG6 6DW, United Kingdom.

E-mail: a.verhoef@reading.ac.uk arid and semiarid regions (Kosmas et al. 1998, 2001; Agam and Berliner 2004, 2006). Under the right atmospheric and soil surface conditions, water is adsorbed from the atmosphere by a thin layer of top soil, generally during the afternoon and evening. The amounts of adsorbed water can be considerable (up to $70 \%$ of daily evaporation; see, e.g., Kosmas et al. 2001). Therefore, quantifying adsorption is important for agricultural water management, surface energy balance studies, ecological studies, and remote sensing investigations (changes in surface soil moisture content will affect land surface properties such as albedo, emissivity, and thermal inertia). For a comprehensive overview of the process of vapor adsorption (and dew formation) in semiarid regions, including measurement methods, the reader is referred to the review of Agam and Berliner (2006). 
To calculate the total amount of water taken up during an adsorption period, $Q$, the following equation is often used (Philip 1957):

$$
Q=\int_{\theta_{\mathrm{i}}}^{\theta_{a}} x \mathrm{~d} \theta=S t^{1 / 2}
$$

where $S$ is the sorptivity in $\mathrm{mm}$ day $^{-0.5}$ and $t$ (day) is time elapsed since the adsorption started. Parameter $S$ lumps together the combined effects of various liquid water and vapor flow mechanisms at work in dry soils (see D. A. Rose 1968).

Equation (1) is based on the assumption that the soil resembles a semi-infinite isothermal column, initially at a uniform water content $\theta_{i}$ and subsequently with the plane $x=0$ (i.e., the soil surface) maintained at $\theta_{a}$ (the water content in equilibrium with the relative humidity of the atmosphere, $h_{a}$; note that in this paper relative humidity will be expressed as a ratio, rather than a percentage, i.e., ranging between 0 and 1 ).

Here, $S$ is not a property of the soil-water system, but a function of $\theta_{i}$ and $\theta_{a}$ (and hence of $h_{a}$ ). Furthermore, D. A. Rose (1968), using various laboratory experiments involving natural soil aggregates and sepiolite (a nonswelling silicate mineral), showed that sorptivity increased with sample temperature and degree of atmospheric turbulence. Even if a typical value of $S$ were available for a particular soil from previously conducted laboratory experiments, the exact nature of the dependency of $S$ on the variables mentioned above (such as $\theta_{i}$ and $h_{a}$ ) will rarely be available. ${ }^{1}$ Using Eq. (1) with a constant $S$ value may therefore give inaccurate estimates of $Q$.

Hence, an equation that explicitly incorporates the effects of soil moisture content, soil temperature, atmospheric humidity, and wind speed (affecting the degree of turbulence) on vapor adsorption is required. Various authors (e.g., Kosmas et al. 1998, 2001; Ninari and Berliner 2002; Agam and Berliner 2004) have employed empirical equations depending on (some) of these variables or related variables (such as cumulative daytime potential evaporation) to describe the adsorption measured at their field sites. However, the constants in these relationships will differ between field sites and vary between seasons.

For a universally applicable approach, it is therefore preferable to calculate the exchange of water vapor be-

\footnotetext{
${ }^{1}$ Note that an exact relation for Eq. (1) is given by $S=2\left(\theta_{i}-\right.$ $\left.\theta_{a}\right)[\bar{D}(\bar{\theta}) / \pi]^{1 / 2}$, where $\bar{D}(\bar{\theta})$ is the weighted-mean diffusivity over range $\theta_{i}$ to $\theta_{a}$, that is, at $\bar{\theta}=1 / 2\left(\theta_{i}+\theta_{a}\right)(\mathrm{D}$. A. Rose 2005, personal communication). A formulation like this can explain some of Rose's experimental findings, but does not allow for the effect of turbulence, for example.
}

tween the soil surface and the atmosphere using the well-known aerodynamic diffusion equation (e.g., Milly 1984):

$$
E=\frac{\rho_{a} C_{p}\left(e_{s, 0}-e_{a}\right)}{\lambda \gamma r_{a}} .
$$

Here, $E\left(\mathrm{~kg} \mathrm{~s}^{-1} \mathrm{~m}^{-2}\right)$ is the water vapor flux, $e_{s, 0}$ is the vapor pressure of the soil air at the soil surface, and $e_{a}$ the actual vapor pressure of the atmosphere (both in $\mathrm{kPa}) ; r_{a}$ is the aerodynamic resistance $\left(\mathrm{s} \mathrm{m}^{-1}\right)$ between the soil surface and the atmospheric measurement level, $\rho_{a}$ is the density of air $\left(\mathrm{kg} \mathrm{m}^{-3}\right), \gamma$ is the psychrometric constant $\left(\mathrm{kPa} \mathrm{K}^{-1}\right), C_{p}$ the specific heat of air at constant pressure $\left(\mathrm{J} \mathrm{kg}^{-1} \mathrm{~K}^{-1}\right)$, and $\lambda$ the latent heat of vaporization $\left(\mathrm{J} \mathrm{kg}^{-1}\right)$. When $E$ is upward (generally defined as positive) evaporation occurs. Water is adsorbed by the topsoil when $E$ is negative. Hence, adsorption can only take place when $e_{s, 0}<e_{a}$.

The vapor pressure of the soil $\operatorname{air}^{2}(\mathrm{kPa})$, is given by

$$
e_{s, 0}=e_{s, 0}^{*} h_{s, 0},
$$

where $e_{s, 0}^{*}$ is the saturated vapor pressure and $h_{s, 0}$ the relative humidity of soil air (-), both at surface level; $e_{s, 0}^{*}$ is a well-known function of temperature (Teten's formula, see Murray 1967):

$$
e_{s, 0}^{*}=0.6108 \exp \left[\frac{17.27 T_{0}}{\left(T_{0}+237.3\right)}\right],
$$

where $T_{0}$ is the surface temperature $\left({ }^{\circ} \mathrm{C}\right)$.

The relative humidity of the soil air, $h_{s, 0}$, can be obtained from the widely used Kelvin equation:

$$
h_{s, 0}=\exp \left[\frac{\Psi_{0} M_{w}}{R\left(T_{0}+273.15\right) \rho_{w}}\right] .
$$

Here, $\Psi_{0}$ is the matric potential $\left(\mathrm{J} \mathrm{m}^{-3}\right.$ or Pa) at the soil surface, $R$ is the universal gas constant $\left(8.314 \mathrm{~J} \mathrm{~mol}^{-1}\right.$ $\left.\mathrm{K}^{-1}\right), M_{w}$ is the molecular weight of water $(0.018 \mathrm{~kg}$ $\left.\mathrm{mol}^{-1}\right)$ and $\rho_{w}$ is the density of water $\left(1000 \mathrm{~kg} \mathrm{~m}^{-3}\right)$.

Alternatively, we can employ adsorption isotherms of water to soil (see Cary et al. 1964) or to clay minerals (see, e.g., Orchiston 1954; Ten Berge 1990), the latter combined with an estimate of the clay content of the soil, to obtain $h_{s}$. The adsorption isotherm is defined as the gravimetric water content of soil (or clay) as a function of soil relative humidity. These adsorption isotherms have a characteristic sigmoidal shape, which mainly depends on the specific surface area of the clay type found in the soil; $h_{s}$ at low water contents (during which vapor adsorption occurs, i.e., $\theta$ at matric poten-

\footnotetext{
${ }^{2}$ Analogous to Eq. (3), $e_{a}$ [required in Eq. (2)] can be found from $e_{a}=e_{a}^{*} h_{a}$, where $e_{a}^{*}$ is the saturated atmospheric vapor pressure, which can be calculated from Eq. (4) with $T_{0}$ replaced by air temperature, $T_{a}$.
} 
tials $<-30 \mathrm{MPa}$ ) is then described as a function of soil water content and the mass of clay per unit volume of bulk soil (see section $2 \mathrm{~b}$ ).

The approach detailed above requires time series of surface moisture content, $\theta_{0}$ \{to calculate $\Psi_{0}$ using a water retention curve, and hence $h_{s, 0}$ [via Eq. (5)], or to derive $h_{s, 0}$ directly from adsorption isotherms $\}, T_{0}, h_{a}$, $T_{a}$, and wind speed, $u$ (required to calculate $r_{a}$ ). The atmospheric variables can be measured using standard meteorological equipment. The soil state variable $T_{0}$ can be monitored relatively easily by currently available methods (e.g., infrared thermometry). However, it is less straightforward to obtain reliable values of $\theta_{0}$ : apart from the fact that the sensors are too large to sample a very thin layer of soil, there is the added problem that at low water contents many capacitance-based sensors are strongly influenced by temperature (see Verhoef et al. 2006). Alternatively, a detailed soil water and heat transfer model (e.g., Milly 1984), coupled to Eq. (2), can be used to predict $\theta_{0}$ and $T_{0}$ (and hence adsorption). However, the reliability of these model estimates of adsorption would be compromised by the uncertainties in the transport coefficients (e.g., the hydraulic and vapor diffusivities; see Scanlon and Milly 1994).

Relatively few data of in situ vapor adsorption are available in the literature (e.g., Kosmas et al. 1998, 2001; Ninari and Berliner 2002; Agam and Berliner 2004). These authors recorded a large temporal and spatial variability of vapor adsorption, with a number of soil and atmospheric variables playing a key role. Among them were 1) (minimum) soil moisture content, surface matric potential, the amount of potential evaporation during the period preceding the adsorption period, and clay content; 2) minimum value and diurnal amplitude of $h_{a}$, and proximity to the sea; and 3) surface cover(age): mulch, stones, vegetation.

The importance of these particular variables makes sense in the light of the adsorption theory discussed above. The variables in group 1 will affect the surface soil air humidity, $h_{s, 0}$, and hence $e_{s, 0}$ [surface temperature, a variable not mentioned in the other studies, will also play a role here, through $e_{s, 0}^{*}$, see Eq. (3)]. Those in group 2 will determine the diurnal course of $e_{a}\left(h_{a}\right.$ is generally higher nearer the sea, and often has a smaller diurnal amplitude), whereas the type and extent of surface cover (group 3), via its effect on roughness parameters and localized wind speed, will influence $r_{a}$. Furthermore, shading (and sheltering) of the soil surface by a canopy will affect $T_{0}$ and moisture content at the soil surface, $\theta_{0}$, (and hence $h_{s, 0}$ ).

In this paper we present measurements of vapor adsorption, and evaporation, obtained with accurate minilysimeters for a bare soil in an olive orchard in southern Spain. We show that vapor adsorption differs considerably over a small scale $(\sim 1 \mathrm{~m})$, due to the effect of the olive trees (affecting the amount and diurnal variation of radiation and therefore the surface energy and water balance, and hence the key surface variables $T_{0}$ and $\theta_{0}$ ). We use Eq. (2) and auxiliary equations, by employing various (sensitivity) analyses, to explain the difference in adsorption between lysimeters installed at various orientations around, and distances from, an olive tree. Furthermore, these equations will be used to explain the considerably larger daily amounts of adsorption found by some other researchers.

Note that this paper does not contain a direct comparison between measured and modeled data of adsorption. The adsorption model needs near-surface soil moisture content as a driving variable. However, in our study this variable was not measured, because currently available soil moisture probes are too large and gravimetric sampling at the surface would have disturbed (the surface of) the lysimeters. It would have been unwise to drive the model with deeper soil moisture content (as measured at $0.025-\mathrm{m}$ depth), because these $\theta$ values are considerably higher than those very near the surface. Instead, the model was inverted to obtain $\theta_{0}$ from measured adsorption. We will show that $\theta_{0}$ obtained in this way has a very plausible course that compares well with findings of others.

The main aim of this paper was to combine wellknown micrometeorological and soil physical equations to allow rigorous study of the process of adsorption in order to urge other workers to move away from empirical equations, because the latter can lead to misleading estimates of vapor adsorption.

\section{Materials and methods}

\section{a. Experimental setup}

The study was conducted in an orchard of 0.5 ha, planted with 35-yr-old olive trees at a spacing of $5 \mathrm{~m} \times$ $5 \mathrm{~m}$ (ground cover $\sim 50 \%$ ), located at the Consejo Superior de Investigaciones Científicas (CSIC) experimental farm La Hampa (Coria del Rio, Seville, Spain, $\left.37^{\circ} 17^{\prime} \mathrm{N}, 6^{\circ} 3^{\prime} \mathrm{W}, 30 \mathrm{~m} \mathrm{MSL}\right)$. The soil is a sandy loam (Xerochrept, $14.8 \%$ clay, $7 \%$ silt, $4.7 \%$ fine sand, and $73.5 \%$ coarse sand).

Eight weighing lysimeters $(0.55 \mathrm{~m} \times 0.55 \mathrm{~m} \times 0.25 \mathrm{~m})$ were uniformly packed with this sandy loam soil (average dry bulk density of $1250 \mathrm{~kg} \mathrm{~m}^{-3}$ ), while ensuring that the original soil stratification was kept intact and bulk density was maintained as close as possible to the in situ values. These lysimeters were installed at differ- 

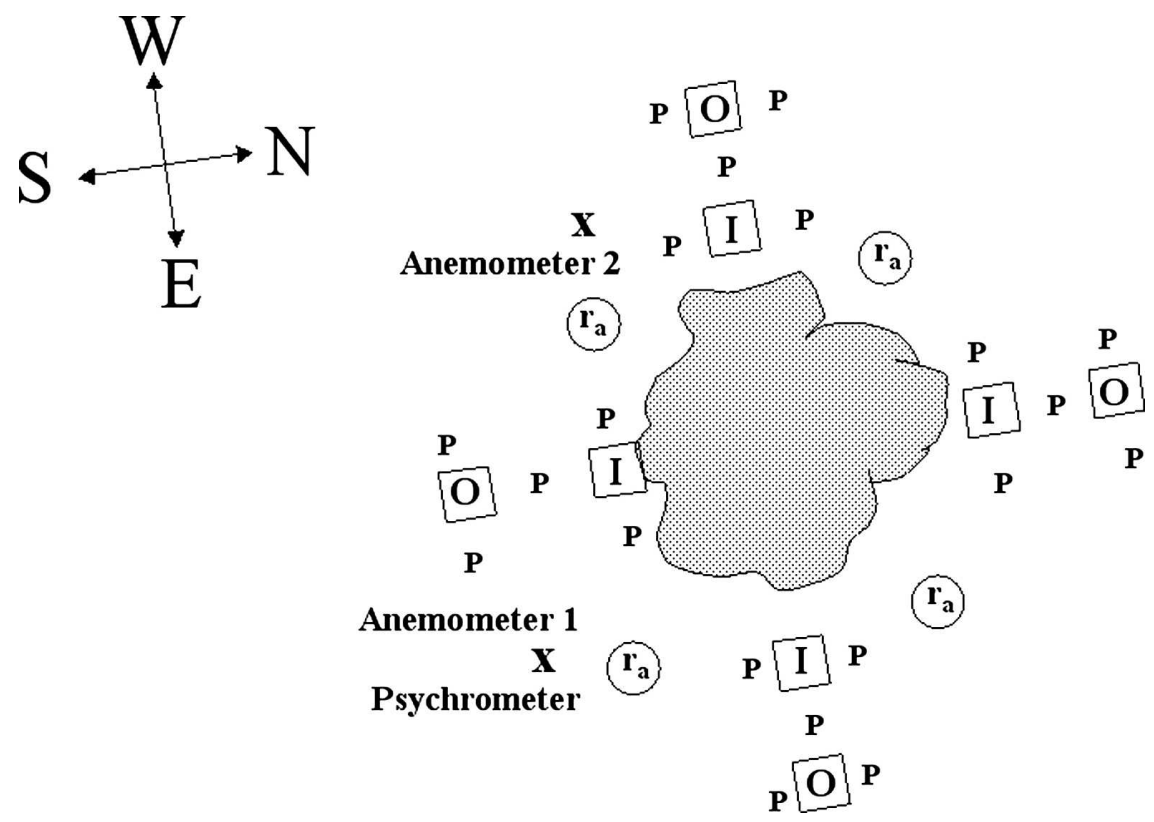

FIG. 1. Schematic diagram showing the experimental setup. Indicated are the eight lysimeters (open squares marked with I for ILS and O for OLS) surrounding the olive tree, and the locations of the instruments used to measure the atmospheric variables $(\mathrm{X})$, aerodynamic resistance $\left(r_{a}\right)$, and incoming solar radiation $(P)$.

ent orientations (N, E, S, W) around, and distances from [1 m: the inner set of lysimeters (ILS), and $2 \mathrm{~m}$ : the outer set of lysimeters (OLS)] the trunk of a single olive tree (Fig. 1). Each lysimeter was made of perspex, a material with a very low thermal conductivity to avoid lateral heat conduction through the lysimeter casing. Changes in weight [with a resolution of $3 \mathrm{~g}$ per lysimeter area $\left(=0.3025 \mathrm{~m}^{2}\right)$; i.e., $\left.0.01 \mathrm{~mm}\right]$ were measured using three $50-\mathrm{kg}$ capacity load cells per lysimeter (model T66, Thames Side, Reading, United Kingdom), and evaporation (weight loss) and vapor adsorption (weight gain) were calculated from these. The effect of temperature on the load cell configuration was found to be negligible [see Diaz Espejo et al. (2005) for more information on the lysimeter electronic setup]. Each lysimeter was equipped with four thermistors (Unitherm EC95 $10 \mathrm{~K}$ thermistor, RS Components, United Kingdom), installed at $0.02,0.05,0.10$, and $0.18 \mathrm{~m}$, respectively, to measure soil temperature, $T_{s}$, and a ThetaProbe (Delta-T Devices, Cambridge, United Kingdom), buried at $0.025 \mathrm{~m}$, to measure soil moisture content, $\theta$.

Aerodynamic resistance was determined from the energy balance of four pairs of adjacent sensors, heated and unheated, placed flush with the soil surface, and located northeast, southeast, southwest, and northwest of the olive tree, using the design and approach of McInnes et al. (1994). Also, one psychrometer and two anemometers (all Delta-T Devices, Cambridge, United
Kingdom) were placed nearby (see Fig. 1), at a height of $0.4 \mathrm{~m}$, to measure air temperature, air relative humidity, and wind speed, respectively.

In addition, 20 sensors (GaAsP photodiodes G1118, Hamamatsu Photonics Corporation, Japan) measuring photosynthetically active radiation (PAR), $R_{p}$, were placed next to and in between the lysimeters (Fig. 1) in order to estimate levels of incoming solar radiation, $R_{s}$, where $R_{s}=2.0 R_{p}$. Note that PAR sensors have a relatively limited spectral range and are therefore not as accurate as pyranometers. Consequently, in this paper $R_{p}$ data are only used to illustrate the approximate differences in $R_{s}$ received by the eight lysimeters. However, the PAR sensors had the advantage of being small, which meant that a considerable number of them could be placed on the ground next to the lysimeters, without running the risk of shading the lysimeters, as would have been the case with larger radiation sensors (e.g., a four-component radiometer).

Measurements were taken every $10 \mathrm{~s}$, and 10-min averages were stored in a Campbell CR21x logger. Irrigation was applied using $4 \mathrm{l} \mathrm{h}^{-1}$ drippers. The lysimeters were irrigated (up to a lysimeter average soil moisture content of $\sim 0.22 \mathrm{~m}^{3} \mathrm{~m}^{-3}$ ) during the afternoon of 4 September 2004 [day of year (DOY) 247] after which a 10-day long dry down took place. Hence, the results presented in this paper are based on data between 5 September (DOY 248) and 13 September 2004 (DOY 256). 
Surface temperature, $T_{0}$, (i.e., $T_{s}$ at depth, $z,=0 \mathrm{~m}$ ), for each lysimeter, was derived from a harmonic analysis (12 harmonics) performed on values of $T_{s}$ measured at $0.02-\mathrm{m}$ depth. Then $T_{0}$ was calculated using these harmonic constants, knowledge of the distance between the installation depth of the thermistor and the surface (i.e., $0.02 \mathrm{~m}$ ), and an estimate of the thermal diffusivity obtained with the Arctangent equation (see Verhoef 2004) which employed measurements of $T_{s}$ at 0.02- and 0.05-m depth.

\section{b. Derivation of surface soil moisture content}

Vapor adsorption will be apparent from increases in lysimeter weight. However, vapor adsorption takes place in a thin layer of topsoil, and it is interesting to see how the water content of this layer varies diurnally and whether the orientation (N, E, S, W) or the location (OLS/ILS) has an effect on its magnitude or diurnal course. Near-surface soil moisture content was not measured, to avoid disturbing the soil surface in the lysimeters, but was calculated using an inverse procedure, as detailed below.

In principle, $\theta_{0}$ can be obtained from the moisture characteristic for this soil, as described by, for example, the van Genuchten model (van Genuchten 1980):

$$
\Psi=-\left[\left(\Xi^{-1 / m}-1\right)^{1 / n}\right] / \alpha .
$$

Here, $\Xi=\left(\theta-\theta_{r}\right) /\left(\theta_{s}-\theta_{r}\right)$, with $\theta_{s}$ and $\theta_{r}$ being the saturated and residual water content, respectively. A value of soil water potential near the surface, $\Psi_{0}$ [required in Eq. (6), when inverting it to obtain $\theta_{0}$ ], can be obtained from Eq. (5), if an estimate of $h_{s, 0}$ is available. The latter was derived by first inverting Eq. (2) to obtain $e_{s, 0}$ [measured values of $E$ and $e_{a}$ were used, while $r_{a}$ was calculated as detailed below, see Eq. (9)]. Subsequently, values of $e_{s, 0}^{*}$ were used, as found from Eq. (4), to get $h_{s, 0}$ [using Eq. (3)]. However, determination of $\theta_{0}$ from the water retention curve involves extrapolation of $\Psi$, based on measurements between 0 and -1.5 $\mathrm{MPa}$, to values well beyond $-1.5 \mathrm{MPa}$ (because $\theta_{0}$ for bare soil in the second stage of drying gets very low) where the curve is extremely steep.

Therefore, in this paper we also explored a second, more direct, way to determine $\theta_{0}$; by employing adsorption isotherms of water to clay minerals (see Orchiston 1954; Ten Berge 1990). These isotherms have a characteristic sigmoidal shape, see Fig. 2, and can be simplified to a set of linear segments, characterized by a single parameter $A_{c}$, following the approach used in Ten Berge (1990). The parameter $A_{c}$ represents the gravimetric moisture content (mass of liquid per mass of dry clay) at $h_{s}=0.8$. The corresponding volumetric water content at this point is then calculated on the basis of

\section{W (kg water/kg dry clay)}

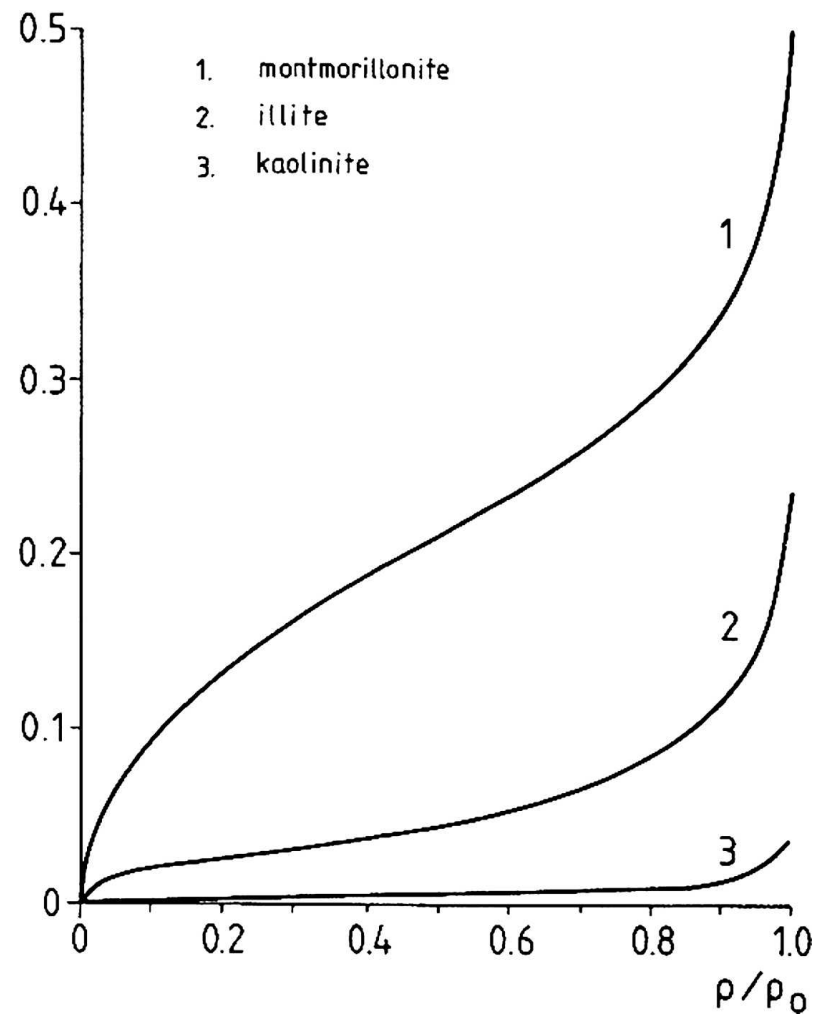

FIG. 2. Adsorption isotherms for water on different clay minerals (reprinted from Ten Berge 1990, as based on Orchiston $1954) ; \rho / \rho_{0}$ denotes the soil relative humidity.

the mass of clay per unit volume of bulk soil, and is here indicated by $\theta_{30}$ (with $-30 \mathrm{MPa}$ being the pressure equivalent of $\left.h_{s}=0.8\right)$ :

$$
\theta_{30}=A_{c} \phi_{c} \rho_{c} / \rho_{w} .
$$

Here, $\phi_{c}$ is the volume fraction of clay and $\rho_{c}$ the density of clay $\left(2650 \mathrm{~kg} \mathrm{~m}^{-3}\right)$. For $\theta_{0}<\theta_{30}, \theta_{0}$ can then be found with (this assumes a linear relationship between $h_{s, 0}$ and $\theta_{0}$ for these low water contents, see Fig. 2)

$$
h_{s, 0}=\frac{\theta_{0}}{\theta_{30}} 0.8 \text {. }
$$

Here, $h_{s, 0}$ is obtained from the procedure detailed above; that is, by inverting Eq. (2) and using Eq. (3) to get $h_{s, 0}$ from $e_{s, 0}$.

For the olive grove $A_{c}$ has been set to 0.06 . This value is based on the adsorption isotherm as determined for a subsample $(\sim 1 \mathrm{~g})$ of this soil using a highly accurate vapor adsorption/desorption apparatus based at the Department of Soil Science, Reading, United Kingdom. A Cahn D-100 recording balance (precision of gravimetric water content of $0.01 \mathrm{mg} \mathrm{g}^{-1}$ ) monitored continuously the weight of a sample while it was sub- 
jected to water vapor at selected vapor pressures. The subsample was obtained from a thoroughly mixed and ground bulk sample of $0.5 \mathrm{~kg}$.

Note that we did not separate the clay from the silt and sand fractions when determining the adsorption isotherm. We therefore calculated $A_{c}$ from $A_{s}$ (found to be $0.019 \mathrm{~g}$ water $/ \mathrm{g}$ soil at $h_{s}=0.8$ ); that is, the $A$ value obtained for the soil sample, using $A_{c}=\left(A_{s} \rho_{b} / \phi_{c} \rho_{c}\right)$, where $\rho_{b}$ is the bulk density of this soil $\left(1250 \mathrm{~kg} \mathrm{~m}^{-3}\right)$. Ten Berge (1990) used $A_{c}=0.01$ for kaolinite and $A_{c}=$ 0.3 for montmorillonite, as based on adsorption isotherms found by Orchiston (1954), so a value of $A_{c}=$ 0.06 seems plausible for our soil, which was reported to contain a mixture of kaolinite and montmorillonite.

Finally, the aerodynamic resistance, required when inverting Eq. (2) to obtain $e_{s, 0}$, was calculated from

$$
r_{a}=104.59 \exp (-0.0976 u)
$$

where $u\left(\mathrm{~m} \mathrm{~s}^{-1}\right)$ is the wind speed obtained from anemometer 1 (see Fig. 1). This equation is based on plotting the night time results of $r_{a}$ versus concurrent measurements of wind speed, and subsequent curve-fitting. Here, $r_{a}$ is the average of the values obtained with the four pairs of adjacent sensors described in section $2 \mathrm{a}$ (no significant differences where found between $r_{a}$ outputs from sensors located at different orientations around the tree). Direct daytime estimates of $r_{a}$ obtained with these sensors during the experiments were unreliable. This was because the two sensors within a pair often received different amounts of radiation, a result of the relatively transparent tree crown. Therefore, $r_{a}$, for both daytime and night time conditions, was determined using Eq. (9) $\left(r^{2}=0.68, n=87\right)$. Ideally, $r_{a}$ would have been calculated with a standard equation based on Monin-Obukhov similarity theory. However, this requires knowledge of the surface roughness parameters and atmospheric stability corrections. The stability correction needs values of sensible and latent heat fluxes, as well as friction velocity, and these variables were not measured. Estimating them (and the roughness parameters) carries with it the risk of introducing uncertainties in $r_{a}$. The exponential relationship given in Eq. (9) fitted the results best. In previous studies (McInnes et al. 1994; Domingo et al. 1999), a power function was used, but it was found that this approach considerably overestimated $r_{a}$ measured at our site, at low wind speeds.

\section{c. Sensitivity analyses}

The theory presented in the introduction and section $2 \mathrm{~b}$ indicates that the amount of adsorption (and evaporation) depends on the complex interplay between surface variables $\theta_{0}\left(\right.$ or $\left.\Psi_{0}\right)$ and $T_{0}$, as well as on atmo- spheric variables $h_{a}$ (affecting $e_{a}$ ), and $u$ (which determines $r_{a}$ ). Furthermore, the clay type and amount will play a role. Therefore, various simple sensitivity analyses were conducted, using Eqs. (2)-(9), to illustrate the dependence of the amount, and timing, of adsorption on these variables.

A single diurnal course was prescribed for all variables involved, based on their average behavior between DOY 249-256 as measured/derived for the olive grove. For example, $h_{a}$ at noon is the average of noon $h_{a}$ values for all eight days. Next, atmospheric or surface variables were changed by adding or subtracting (e.g., $\left.h_{a}+0.05\right)$, or by changing the amplitude (e.g., 1.1 $T_{0}$ ). In some cases one variable at a time was changed, in other cases two in conjunction.

\section{Results and discussion}

\section{a. Diurnal evaporation and vapor adsorption}

Figure 3 shows the directly measured diurnal course (between DOY 250 and 253) of positive (upward, i.e., evaporation) and negative (downward, i.e., adsorption) $E$ for the outer and inner lysimeters (OLS and ILS, respectively), for the four orientations around the olive tree (starting with east in Fig. 3a, followed by south, etc.). Although $E$ varies considerably on a 30-min time scale (due to changes in atmospheric variables such as wind speed and incoming radiation, see Fig. 5), differences in $E$ between lysimeters as a result of orientation and distance from the tree trunk are clearly visible in Fig. 3. Generally, adsorption is more likely to occur for the OLS, and when it occurs its values are larger.

To make the diurnal courses of $E$ better discernable, Fig. 4 shows the separate values of period-average diurnal evaporation (to be referred to as $E^{+}$) and vapor adsorption $\left(E^{-}\right)$as measured for the eight lysimeters surrounding the olive tree (starting with east, in Figs. 4a,b,c,d, respectively). As in Fig. 3, in each subgraph of Fig. 4 the OLS and ILS are compared. For each half hour, $E$ (whether positive or negative) is defined by

$$
\overline{E_{j}}=\sum_{i=1}^{n} E_{i j} / n,
$$

with $j=1,48$ (i.e., the half hour during the day) and $i$ the day number [starting at $i=1$ for DOY 249, whereas $i=n(=8)$, for DOY 256]. This explains why in Fig. 4 evaporation and adsorption can seemingly take place during the same timeslot. This is the result of the fact that on certain days evaporation may have taken place between, for example, 1500 and 1530 UTC (e.g., on days at the start of the dry-down period), whereas on subsequent days the combination of surface and atmospheric conditions dictated adsorption to occur during 

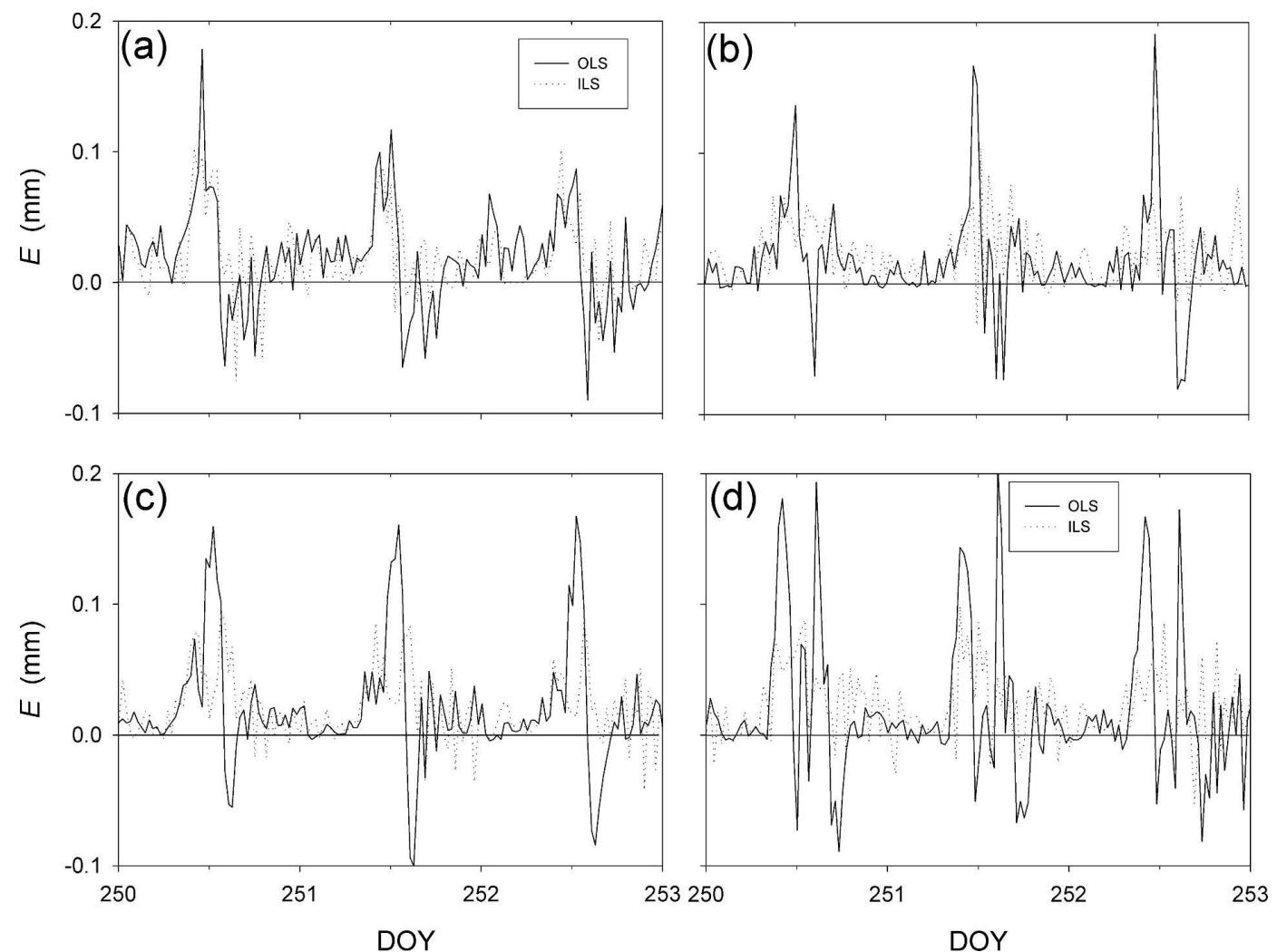

FIG. 3. The measured diurnal course (between DOY 250 and 253) of positive (upward) and negative (downward, i.e., adsorption) $E$-flux for the OLS and ILS to the (a) east, (b) south, (c) west, and (d) north of the olive tree.

this time slot. Figure 4 therefore also carries within it information on the relative likelihood of adsorption occurring during a particular time interval.

Figure 4 shows that vapor adsorption can start as early as 1100 UTC (=LT - 2), see Fig. 4d (OLS), but generally it begins just after midday for the OLS and between 1500 and 1600 UTC for the ILS. During the afternoon there is often a sudden increase in atmospheric humidity (e.g., on DOY 255 from 0.29 to 0.42 , data not shown), which increases the vapor pressure gradient and hence favors adsorption. This increase in $h_{a}$, or at least the leveling off of its sharp decline started during the morning, is caused by a sudden change in wind direction, from southeast to southwest, bringing in moister air that originates from the Mediterranean Sea (approximately $80 \mathrm{~km}$ to the southwest of the Coria experimental site). Vapor adsorption is larger for the OLS than for the ILS.

Significant vapor adsorption generally ceases around 1800 UTC, because $e_{s, 0}$ reaches values that are higher than $e_{a}$ again (the sign of $E$ will depend on the sign of the gradient $e_{s, 0}-e_{a}$, as explained in the introduction). The water vapor adsorbed during the afternoon increases $\theta_{0}$, see Fig. 7 , and hence $e_{s, 0}$. Therefore, during the night, all lysimeters, and OLS(E) (see Fig. 4a) in particular, generally exhibit a small positive $E$.

Figure 4 also shows that there is a large difference in instantaneous daytime $E^{+}$between the OLS and ILS; maximum values of $E^{+}$are generally considerably higher for the OLS. The timing and magnitude of the peaks in $E^{+}$are related to the radiation regime: Fig. 5 shows period-average $R_{s}$ for all eight lysimeters. For example, the lysimeters placed to the west of the tree received most of their radiation during the afternoon (Fig. 5c), and a similar trend can be observed for the evaporation (Fig. 4c). The same applies to the observed time lag between the OLS and ILS in this graph.

\section{b. Daily amounts of evaporation and adsorption}

The total daily amounts of $E^{+}$and $E^{-}$between DOY 248 and 256 are shown in Fig. 6. The amount of $E^{+}$ declined between DOY 248 and 256, mainly as a result of the drying of the soil surface layer (daily sums of $R_{s}$ stayed roughly the same over this period). Absolute values of $E^{-}$(i.e., adsorption) generally increased throughout the dry down, although a considerable temporal variability can be observed for each lysimeter. Evaporation (during the latter part of the dry down) 

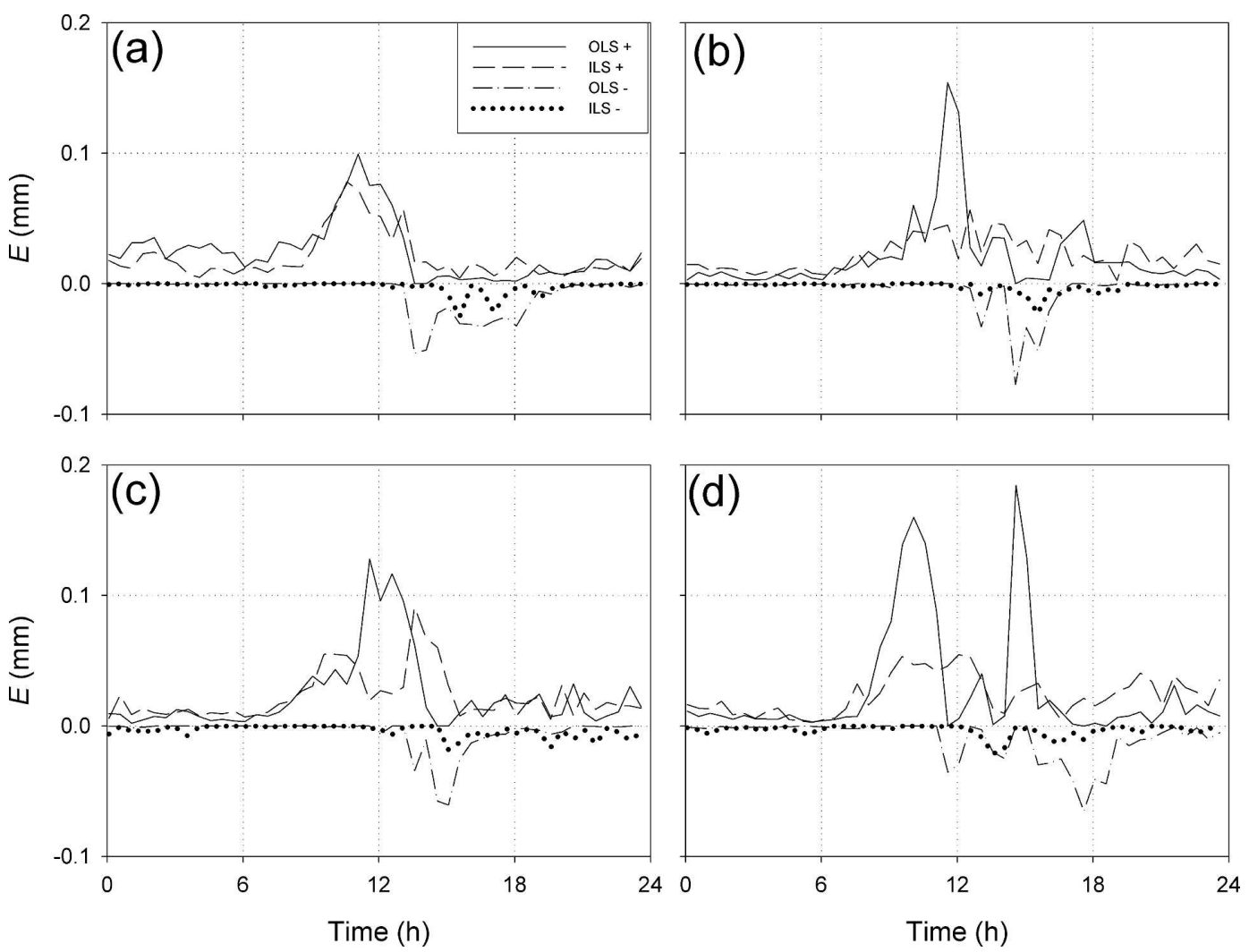

FIG. 4. The diurnal course of period-average (DOY 249-256) positive (upward) and negative (downward) $E$-flux for the OLS and ILS for the same locations as indicated in Fig. 3.

and adsorption are generally lower for the ILS than for the OLS. Furthermore, for the ILS there is less variability in $E^{+}$and $E^{-}$when comparing the lysimeters located at different points of the compass.

Between (OLS versus ILS) and within (N, S, E, W) treatment differences of $E^{+}$and $E^{-}$, as well as the temporal variability of $E^{-}$in particular, are the result of (small) spatial and day-to-day differences in surface and atmospheric conditions (this will be discussed more fully in the section dealing with the sensitivity analyses).

The absolute amounts of $E^{-}$are approximately $25 \%-50 \%$ of $E^{+}$toward the end of the 10 -day period. These rates of adsorption will not play a large role in the water balance of the olive grove (the trees would obtain their water from much deeper soil layers). However, these daily adsorption rates may be an important water input for nonirrigated small herbaceous plants growing in these regions, where rainfall is entirely absent during the summer months (see also Rose 1996).

On the other hand, the increased surface moisture content will affect the surface properties of the soil substrate in between the trees (e.g., soil emissivity will be slightly higher and soil albedo will be lower compared to similar sites without adsorption) and hence the radiation and energy balance.

\section{c. Surface variables}

\section{1) Surface SOIL MOISTURE CONTENT}

Figure 7 shows the period-average $\theta_{0}$ for the same time span as used in Fig. 4 [average $\theta_{0}$ was calculated using an equation analogous to Eq. (10)]. Here, $\theta_{0}$ was calculated with Eq. (8); this procedure involved using measured instantaneous values of $u$ (to obtain $r_{a}$ ), $E, e_{a}$ and derived $T_{0}$, to estimate $e_{s, 0}$ and hence $h_{\mathrm{s}, 0}$. In Eq. (7), $\phi_{c}=0.148($ see section $2 \mathrm{a})$, with $A_{\mathrm{c}}=0.06, \theta_{30}=$ $0.0235 \mathrm{~m}^{3} \mathrm{~m}^{-3}$.

For both the ILS and OLS, $\theta_{0}$ reaches a minimum around midafternoon. Maximum values are found around 0800 UTC. A very similar diurnal course was obtained by Agam and Berliner (2004), who measured $\theta_{0}$ gravimetrically, for dry topsoil in the Negev desert.

Furthermore, Fig. 7 illustrates that $\theta_{0}$ (OLS) is generally lower than $\theta_{0}$ (ILS) during the daytime hours (at most by about $0.005 \mathrm{~m}^{3} \mathrm{~m}^{-3}$ ), in particular during the afternoon. Although the absolute difference may not seem much, its relative effect is large in terms of $h_{s, 0}$ 


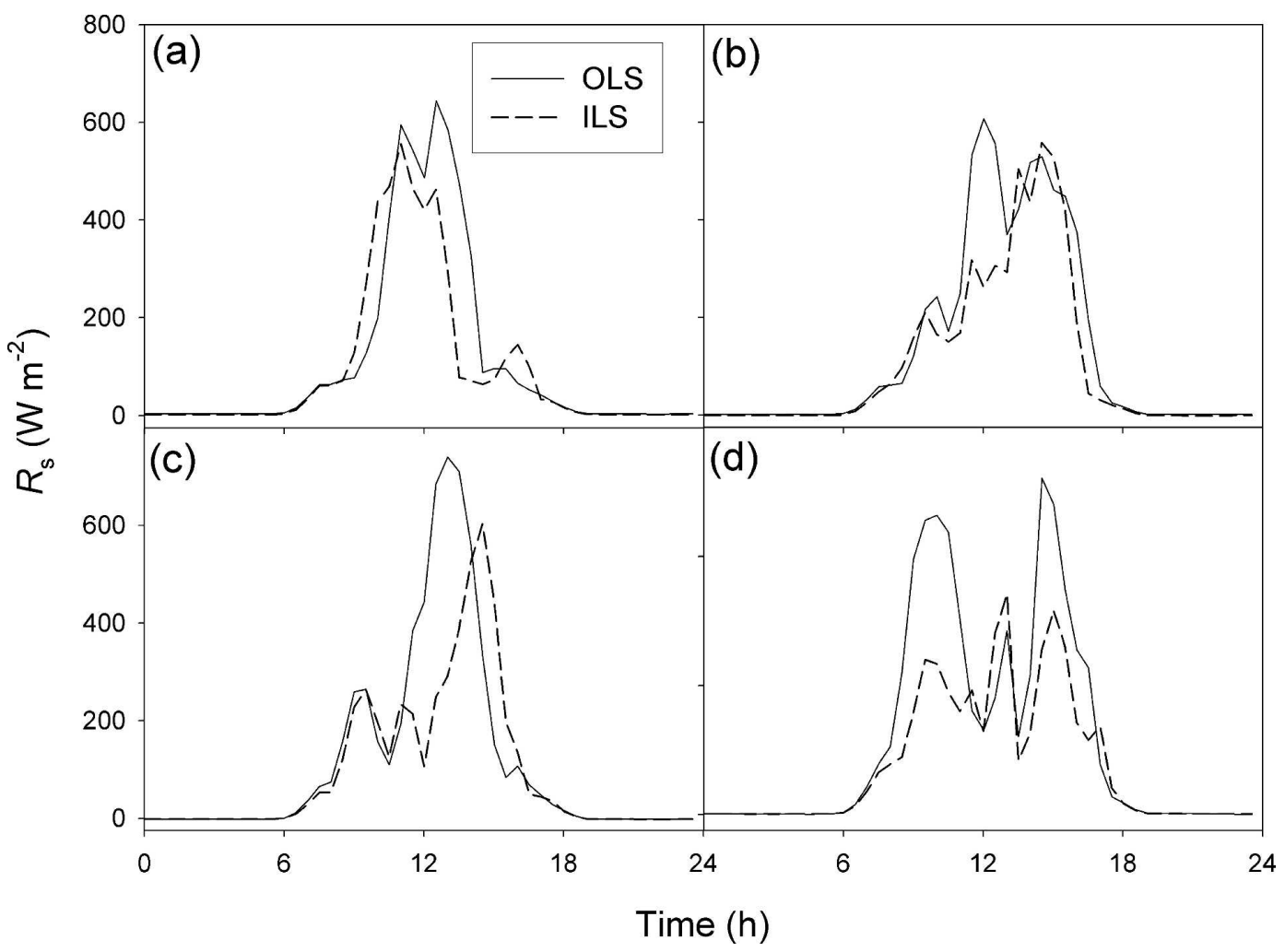

FIG. 5. The diurnal course of period-average (DOY 249-256) shortwave incoming radiation received by the OLS and ILS for the same locations as indicated in Fig. 3.

[see Eq. (8)] and hence $e_{s, 0}$, and it therefore affects the likelihood of occurrence and amount of adsorption (see also section $3 \mathrm{~d})$.

Here, $\theta_{0}$ was also calculated using the combination of Eq. (5) (the Kelvin equation; to get $\Psi_{0}$ from $h_{s, 0}$ as derived from the diurnal $E$ course and driving variables, see above) and Eq. (6) (the van Genuchten equation; to obtain $\theta_{0}$ from $\Psi_{0}$ ). A multiregression analysis was used to estimate the van Genuchten parameters for the soil at La Hampa farm, employing simultaneously measured $\Psi$ and $\theta$ data. It was found that best fit parameter values for $\theta_{s}$ and $\theta_{r}$ were 0.4 and $0.0 \mathrm{~m}^{3} \mathrm{~m}^{-3}$, respectively, while parameter $n$ equaled $1.3852, \alpha=$ $0.1535 \times 10^{-3} \mathrm{~Pa}^{-1}$, and $m=1-1 / n=0.2781$. An example of its course is given in Fig. $7 \mathrm{~b}$ for OLS(S) and ILS(S); courses of $\theta_{0}$ for the other orientations were very similar. Here, $\theta_{0}$ roughly varied between 0.005 and $0.02 \mathrm{~m}^{3} \mathrm{~m}^{-3}$; minimum values of $\theta_{0}$ were similar to the $\theta_{0}$ calculated via the adsorption isotherm. However, the maximum values of $\theta_{0}$ were lower and the slope of the decrease during the day and the increase during the night was somewhat less. The difference between the OLS and ILS was less pronounced as a result of the exponential shape of the Kelvin equation. Because of the lack of in situ data for $\theta_{0}$, it is not immediately obvious which estimate is more realistic. However, both courses of $\theta_{0}$ follow the typical diurnal variation measured by Agam and Berliner (2004; see also, e.g., Fig. 8 in C. W. Rose 1968 and Figs. 1-4 in Nakayama et al. 1973).

When predicting adsorption, the approach using the adsorption isotherm has the advantage that the effect of clay content and type can be included in a relatively straightforward manner, rather than through changes in van Genuchten parameters, which are often not available.

Soil moisture data were available from Thetaprobe measurements, but only at $0.025-\mathrm{m}$ depth. At this depth, $\theta$ was considerably higher than $\theta_{0}$ (average values were around $0.18 \mathrm{~m}^{3} \mathrm{~m}^{-3}$ ); this is caused by the steep soilmoisture gradients that occur in the top few centimeters of drying bare soils. When these $\theta$ data were corrected for temperature effects (M. El-Bishti 2005, personal communication), the occurrence of its minimum and maximum values coincided with those found for $\theta_{0}$.

\section{2) Surface temperature}

Figure 8 shows the surface temperatures for the eight lysimeters. As mentioned in section $2 \mathrm{a}, T_{0}$ was not measured directly, but calculated from the soil temperature 

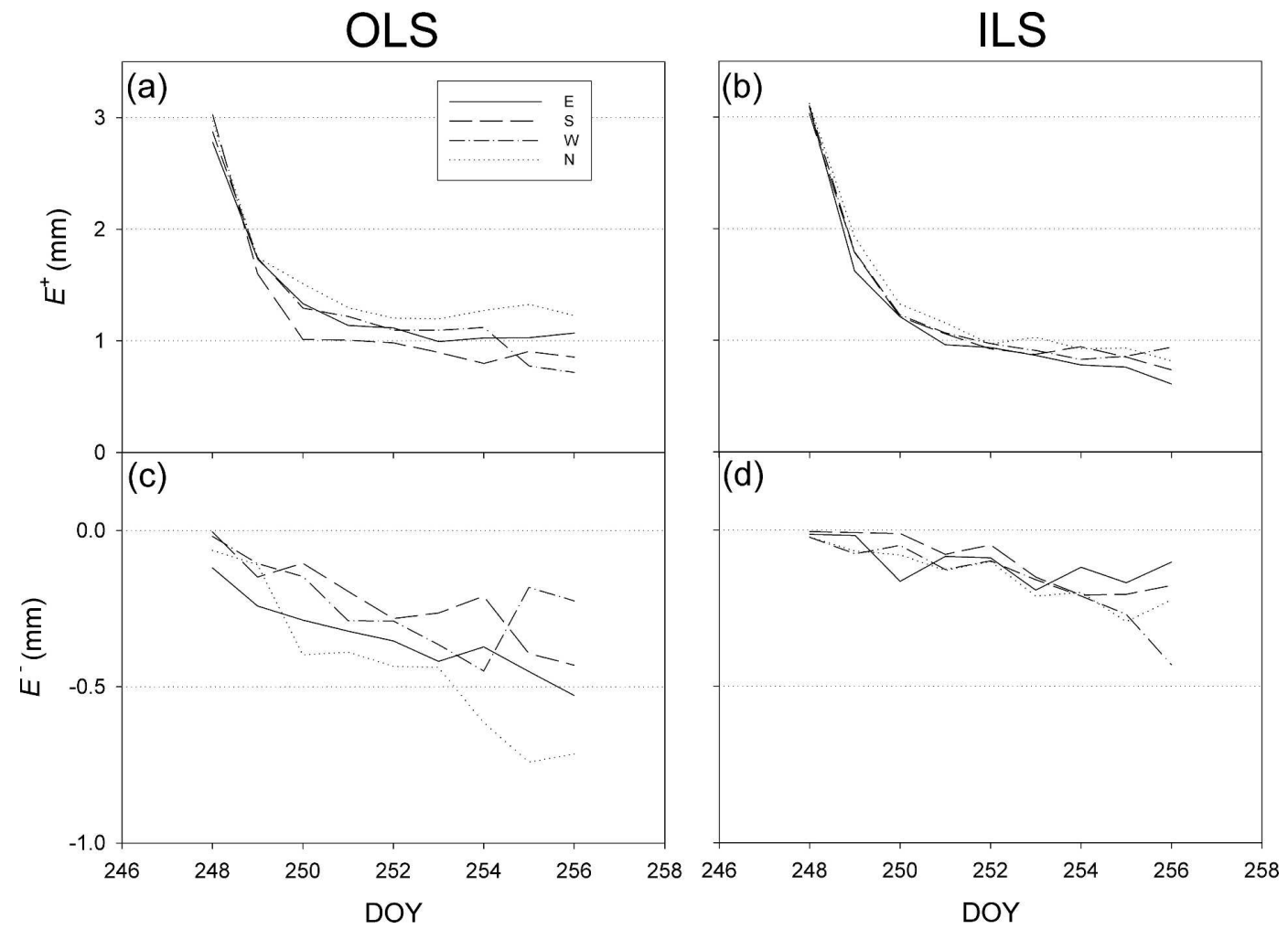

Fig. 6. Total daily amounts of (a), (b) water loss (i.e., positive $E$ ) and (c), (d) water gain (i.e., negative $E$ or adsorption), for the OLS and ILS, respectively.

measured at $0.02 \mathrm{~m}$. This procedure will cause some uncertainty in the estimate of $T_{0}[O( \pm 1 \mathrm{~K})]$. The diurnal course of $T_{0}$ shown in Fig. 8 bears large similarities to the course of $R_{s}$ (Fig. 5) and $E^{+}$as measured for the various lysimeters. During the day, $T_{0}$ is generally larger for the OLS (they receive more solar radiation, as shown Fig. 5).

Surface temperature affects $e_{s, 0}$ (through $e_{s, 0}^{*}$ ) and hence evaporation and adsorption [see Eq. (2)]. During periods of water loss (positive $E$ ), a higher $T_{0}$ will enhance $E$. However, a higher $T_{0}$ suppresses adsorption (see also Fig. 11). This means that the fact that $\theta_{0}$ (OLS) $<\theta_{0}$ (ILS) had a larger effect on adsorption than that $T_{0}$ (OLS) $>T_{0}$ (ILS). Therefore, the focus of the remainder of the paper will be on the effect of $T_{0}$ and $\theta_{0}$ on vapor adsorption, as illustrated using simple sensitivity analyses.

\section{d. Results of sensitivity analysis conducted for the olive grove data}

Figure 9 shows the driving variables used in the sensitivity analysis conducted for the olive grove. The diurnal courses depicted are period-averages [between DOY 249 and 256, calculated analogously to Eq. (10)] of the variables needed to calculate evaporation and adsorption employing Eqs. (2)-(4), and Eqs. (7)-(9). In Figs. 9a,b, $\theta_{0}$ and $T_{0}$ are the averages of all four OLS and ILS (the individual data were shown in Figs. 7 and 8).

The differences in surface variables between the OLS and ILS, especially between 1100 and 1800 UTC, are apparent. During this period $\theta_{0}$ (OLS) is at most 0.003 $\mathrm{m}^{3} \mathrm{~m}^{-3}$ lower than $\theta_{0}$ (ILS). Here, $T_{0}$ (OLS) is up to $5^{\circ} \mathrm{C}$ higher than $T_{0}$ (ILS). Relative humidity varies between 0.35 and 0.85 , and wind speed is low, ranging between $0-1 \mathrm{~m} \mathrm{~s}^{-1}$. Its highest values are recorded between 1200 and 1800 UTC.

The sensitivity analysis will focus on the ILS, because perturbation of the driving variables will have a very similar effect on the $E$ flux of the OLS. Note that the purpose of this exercise is not to predict $E^{-}$for our site ( $\theta_{0}$ was derived from measurements of $E^{-}$, so it is not an independently measured variable), but to explore the sensitivity of $E^{-}$to (small) changes in surface and atmospheric variables.

Figure 10 shows the calculated reference diurnal course of $E$ (i.e., using the values shown in Fig. 9) for the OLS and ILS. When using the period-average values of driving variables, the set of formulae comprising Eqs. (2)-(4) and Eqs. (7)-(9) predicts adsorption to occur for the OLS only. Vapor adsorption occurs be- 

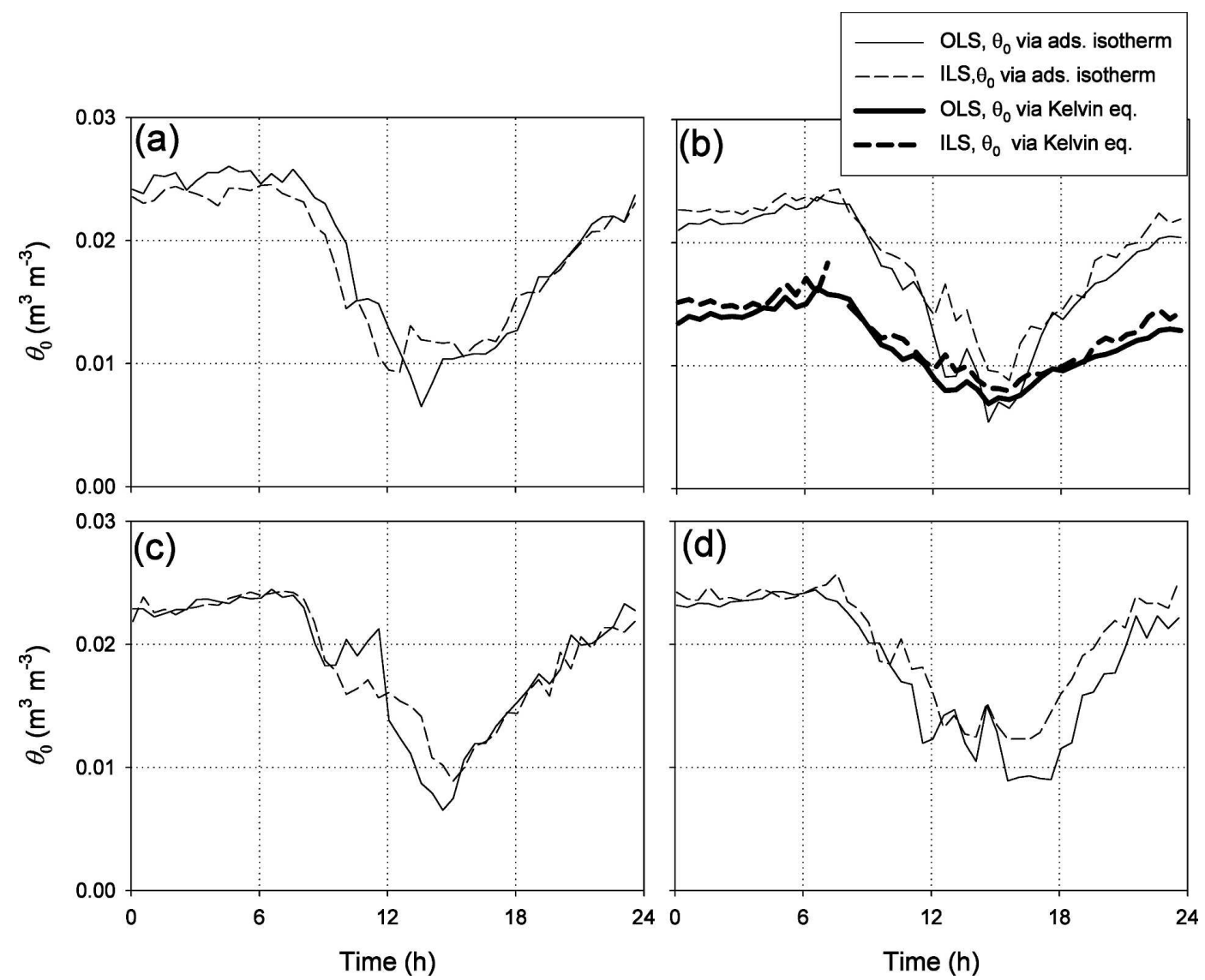

FIG. 7. The diurnal course of period-average (DOY 249-256) surface soil moisture content, $\theta_{0}$, for the OLS and ILS for the same locations as indicated in Figs. 3, 4, and 5; $\theta_{0}$ was calculated using the set of formulas comprising Eqs. (2)-(4), and Eqs. (7)-(9) [for the bold lines in Fig. 7b, Eqs. (2)-(6) and Eq. (9) were used to calculate $\theta_{0}$ ].

tween the mid- and late afternoon (see also Fig. 4). The ILS shows a larger $E^{+}$between 1500 and 2400 UTC.

Figure 11 depicts the ILS reference course (continuous line, i.e., calculated using the values of driving variables shown in Fig. 9) together with results of the model run for which $\theta_{0}$ was diminished by $0.003 \mathrm{~m}^{3} \mathrm{~m}^{-3}$ (the dashed line; this will bring the ILS daytime values close to those measured for the OLS, see Fig. 9a). This moderate decrease in $\theta_{0}$ (in the absolute sense) caused modeled $E$ to be negative throughout virtually the entire 24-h cycle. The largest negative values of $E$ occur when $\theta_{0}$, and hence $e_{s, 0}$, is lowest.

However, a decrease in $\theta_{0}$ is usually accompanied by an increase in $T_{0}$ (a drier soil is generally warmer, as a result of reduced evaporation and lower thermal conductivity), as Fig. 9b shows. Therefore, the dotted line in Fig. 11 shows the evolution of $E$ when $\theta_{0}$ was decreased, while the amplitude of $T_{0}$ was increased by $10 \%$. This simulation indicated that in this case adsorption from the ILS would occur between 1500 and 1900 UTC. The effect of changing only surface temperature (curve denoted by -.-.-. in Fig. 11) is for $E$ to be positive at all times, at values larger than the reference $E$ (because of larger values of $e_{s, 0}^{*}$ ). The larger $T_{0}$ values found for the OLS (Fig. 8) therefore prevented the difference between measured OLS and ILS adsorption to become more pronounced.

Figure 12 shows the effect of an increase in relative humidity. The effect of a positive bias in $h_{a}$ as well as a relative increase in $h_{a}\left(1.1 h_{a}\right)$ are shown (Kosmas et al. 2001 indicate that both the minimum $h_{a}$ and the amplitude of $h_{a}$ are important in the process of water vapor adsorption). An increase in $h_{a}$ leads to the occurrence of vapor adsorption during the afternoon and early night $\left(e_{a}\right.$ increases compared to the reference scenario, causing $e_{s, 0}-e_{a}$ to attain negative values). The increase in $e_{a}$ will also cause $E^{+}$values to go down. A relative, rather than absolute increase in $h_{a}$, causes adsorption to start later in the afternoon, because the comparatively low $h_{a}$ values in the afternoon $(\sim 0.3)$ cause $h_{a}$ to increase by 0.03 , rather than 0.05 . These results show that a change in $h_{a}$, for example through a change in wind 

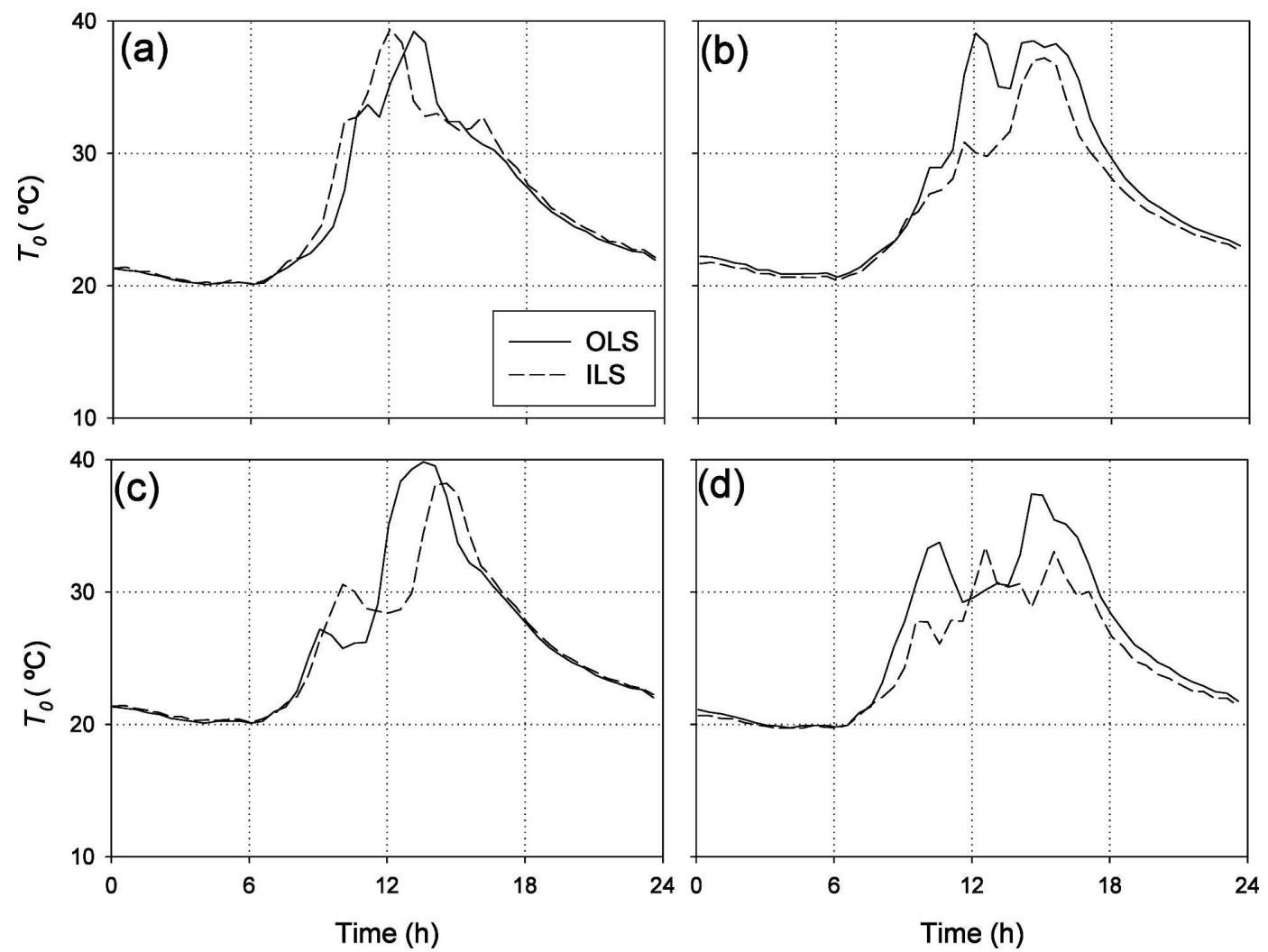

FIG. 8. The diurnal course of period-average (DOY 249-256) surface soil temperature, $T_{0}$, for the OLS and ILS for the same locations as indicated in Fig. 7. Here, $T_{0}$ was derived from a harmonic analysis of soil temperature, $T_{s}$, measured at $0.02 \mathrm{~m}$ and a value of thermal diffusivity, obtained using the arctangent equation (Verhoef 2004).

direction, bringing in a more humid air mass (either from a nearby large water body, or even from an extensive area of irrigated agricultural land), can change the likelihood of the occurrence of adsorption considerably. However, at the same time the surface temperature and soil moisture content need to be such that $e_{s, 0}<e_{a}$.

Other sensitivity analyses were performed (results not shown). For example, an increase in clay content by $2 \%\left(\phi_{c}=0.168\right.$ rather than 0.148$)$ caused an adsorption of $0.63 \mathrm{~mm}$ for the ILS run with reference driving variables (compared to $0 \mathrm{~mm}$ when $\phi_{c}=0.148$ ). In this case, evaporation took place between 0930 and 1430 UTC only, compared to the reference case where $E$ was always positive. An increase in wind speed $[u=u$ (Fig. $9 \mathrm{~d})+1.0]$, and hence a decrease in $r_{a}$, caused absolute values of $E$ to increase by $10 \%$ [see also D. A. Rose (1968), who compared sorptivity for soil columns exposed to still and turbulent air]. A change in the parameter $A_{c}$, describing the shape of the adsorption isotherm for $h_{s}<0.8$, will also have a large effect on the evaporation/adsorption process, as will be discussed in section $3 \mathrm{e}$.
This sensitivity analysis treats the changes in driving variables of the soil-atmosphere system in a simplified manner. Furthermore, it ignores some of the interactions and feedbacks between them. It shows, however, that a relatively small difference in driving variables (caused by different amounts of radiation throughout the day or a change in wind direction) can make the difference between the occurrence and the absence of adsorption, even on a very local scale.

\section{e. Comparison with other studies}

The maximum amount of adsorption at the olive grove ranges between $\sim 0.2$ and $0.5 \mathrm{~mm} \mathrm{day}^{-1}$ for the majority of the lysimeters, to approximately $0.7 \mathrm{~mm}$ day $^{-1}$ for OLS (N). Agam and Berliner (2004) measured vapor adsorption for a bare sandy loam (13\% clay, $15 \%$ silt, and $72 \%$ sand) in the Negev desert (60 $\mathrm{km}$ from the coast). They used a microlysimeter, as well as the water gains computed from soil water content changes in soil samples taken in the vicinity of the lysimeter, to calculate water adsorption. Their data were gathered over eight diurnal periods during the months 

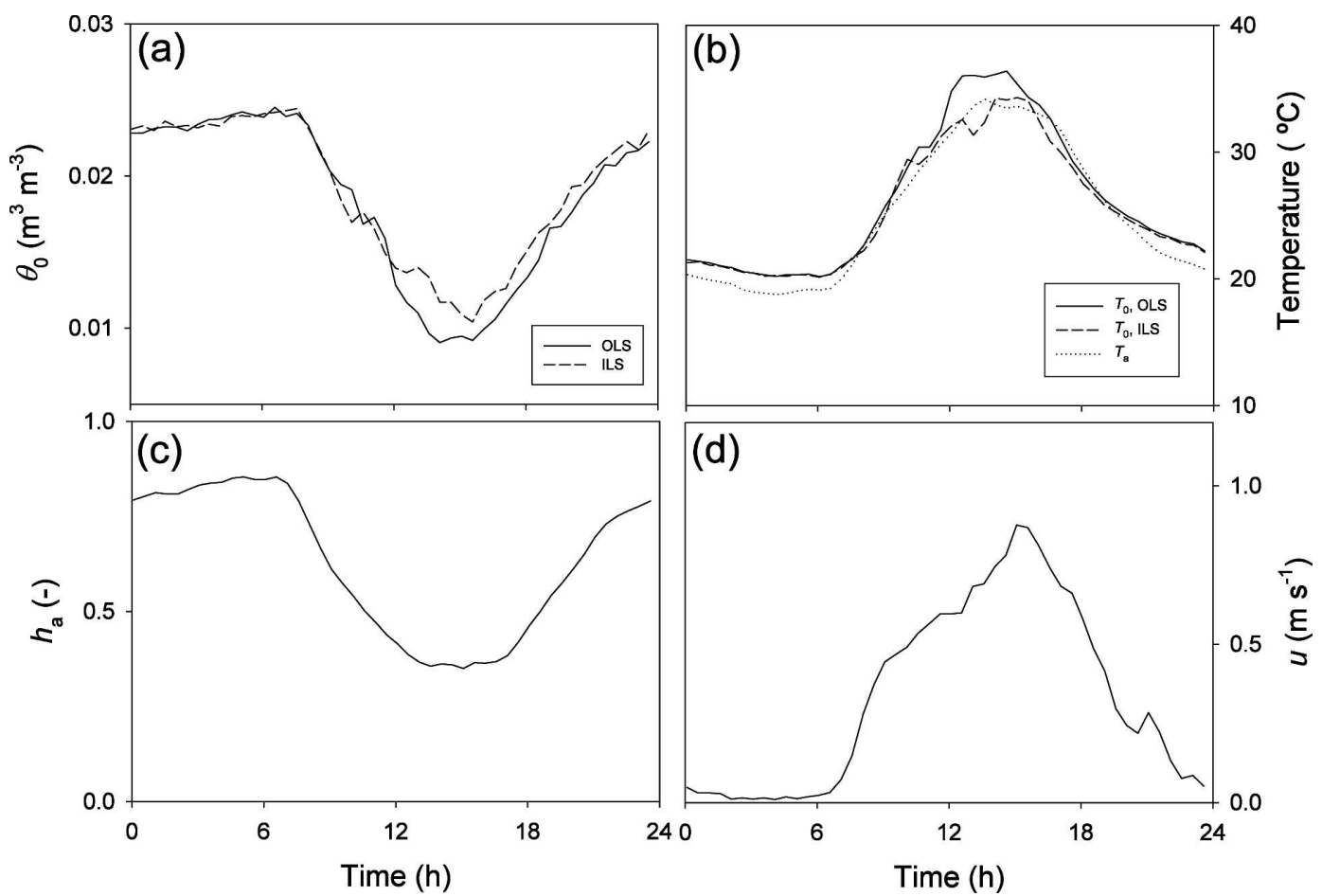

FIG. 9. The (period average) reference driving variables used in the sensitivity analysis described in section $2 \mathrm{c}$. (a) The surface soil moisture content [average of four (E, S, W, N) lysimeters] for the OLS and ILS, respectively. (b) The surface temperatures (average of four lysimeters) for the OLS and ILS, respectively. Also indicated is the air temperature. (c) The relative humidity of the air, and (d) the wind speed.

of June-October. Agam and Berliner found values of total water adsorption per adsorption period ranging between 0.18 and $0.33 \mathrm{~mm}$ day $^{-1}$; that is, slightly lower than the values found at the Coria experimental site. This could have been caused by the fact that their clay contents were somewhat lower $(13 \%$ compared to

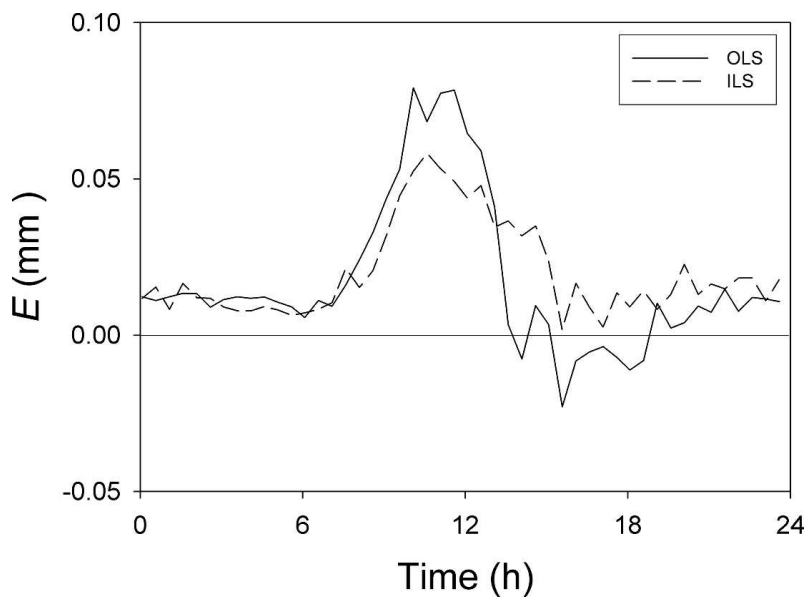

FIG. 10. Values of $E$-flux (with negative values being adsorption) for the average OLS and ILS as predicted by Eq. (2) [with Eqs. (3), (4), (7), (8), and (9) being auxiliary equations], using the surface and atmospheric driving variables as depicted in Fig. 9.
$14.8 \%$, but note that the type of clay will also play a large role). Furthermore, the daytime surface temperatures of a hot, exposed desert soil will have been larger than those of the partly shaded soil of the olive grove, thereby suppressing adsorption; $\theta_{0}$ and range of $h_{a}$ were very similar to those found for the Coria site.

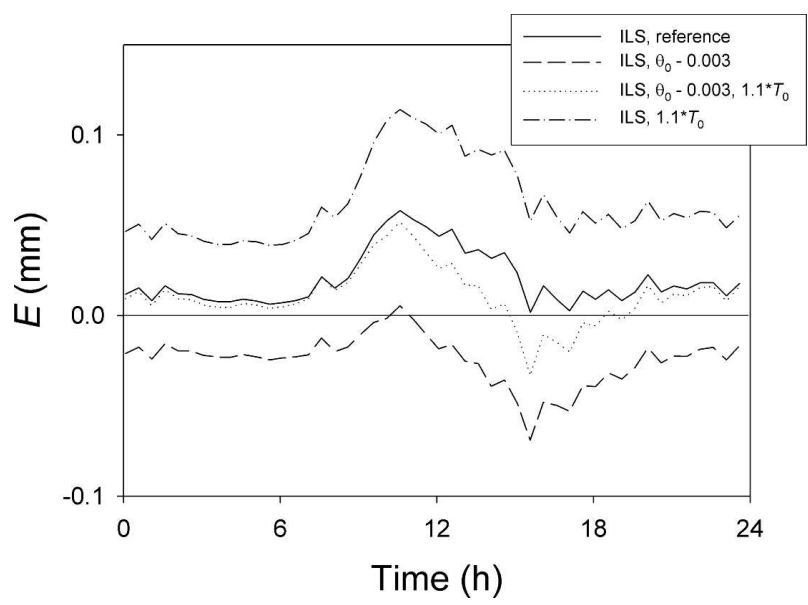

FIG. 11. Diurnal course of $E$ as predicted for the average ILS using the input given in Fig. 9 (solid line, called reference), together with predictions of $E$ when either $\theta_{0}, T_{0}$, or both have been perturbed. 


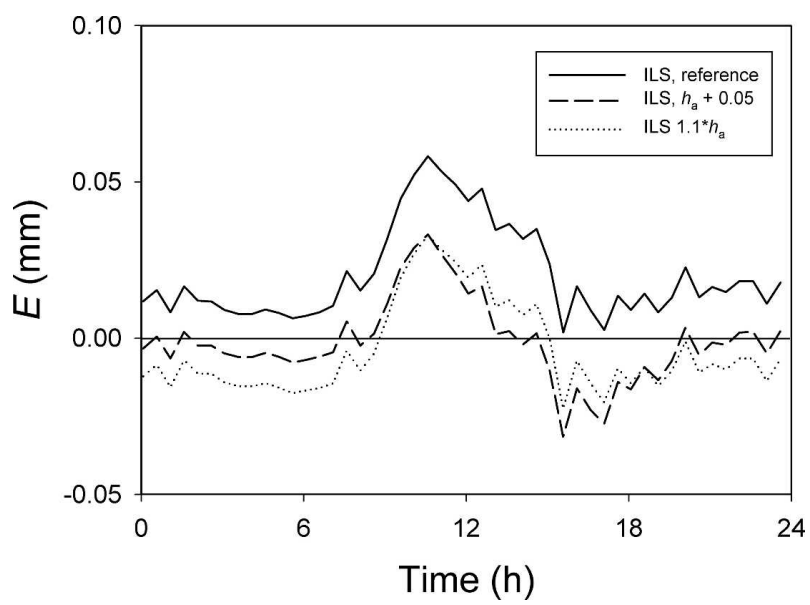

FIG. 12. Results of a sensitivity analysis (see above), where $E$ (ILS) has been calculated using increased values of $h_{a}$ (either by adding a constant value, i.e., 0.05 ) or by multiplying all values shown in Fig. 9c by 1.1. The reference $E$ is also shown.

Kosmas et al. (2001, hereafter K01), used a combination of time domain reflectometers and weighing lysimeters to measure soil moisture content and vapor adsorption of soils in hilly areas under semiarid climatic conditions in Greece, between May and October. Their sites varied in clay content (ranging from $1 \%$ to $35 \%$ ), land use (bare soil, rain-fed crops, or shrubby natural vegetation), and the influence of sea winds (all sites were within $10 \mathrm{~km}$ from the coast, but at some sites mountains restricted the direct effect of air currents blowing from the sea).

The site with clay contents similar to ours is their Antissa site (16.8\%). The values of adsorption for this site (shrubby natural vegetation) range from about 0.05 to $3.7 \mathrm{~mm}$ day $^{-1}$, between $\theta$ values (measured at $5-\mathrm{cm}$ depth) of $0.05 \mathrm{~m}^{3} \mathrm{~m}^{-3}$ and $0.47 \mathrm{~m}^{3} \mathrm{~m}^{-3}$. These maximum adsorption values, and the range of soil moisture contents for which adsorption occurs, are much larger than those measured in our olive grove or the Negev desert soil.

Furthermore, K01 made the observation that vapor adsorption increased with increasing $\theta$, (their Fig. 9), which at first sight appears to go against the vapor adsorption theory and the findings presented for the olive grove in Fig. 11. Additional (sensitivity) analyses detailed below will be used to explain these findings.

First, we generally do not expect adsorption to occur at high $\theta$ values (in K01's case up to $0.47 \mathrm{~m}^{3} \mathrm{~m}^{-3}$ !); this phenomenon is usually linked to fairly dry soils (because only below $\theta_{30}$ will $h_{s, 0}$ generally drop enough to allow adsorption to take place). However, the $\theta$ values given in $\mathrm{K} 01$ are measured at a depth of $0.05 \mathrm{~m}$. Values of $\theta_{0}$ would therefore have been considerably lower

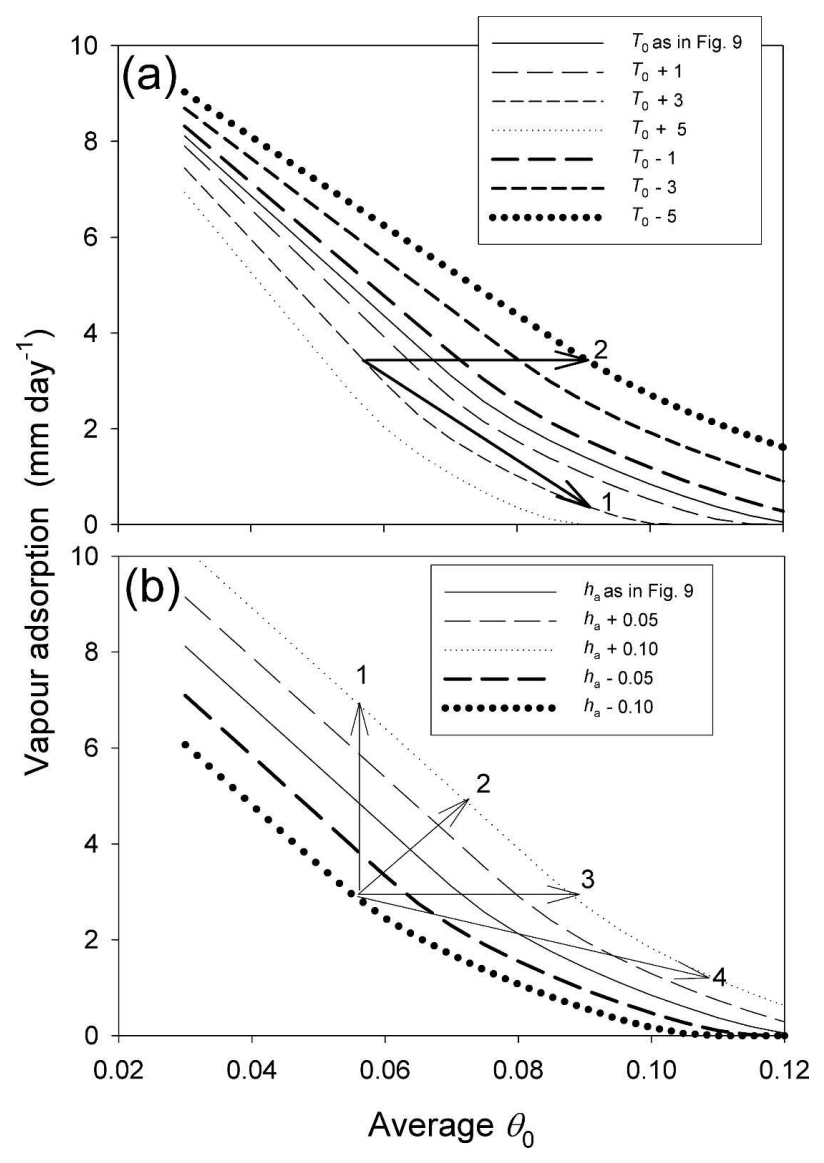

FIG. 13. Vapor adsorption as a function of $\theta_{0}$, calculated using Eqs. (2)-(4) and Eqs. (7)-(9), with $A_{c}=0.3$ and $\phi_{c}=0.168$ in Eq. (7) [these values describe the likely clay type and measured clay content at the Antissa site of Kosmas et al. (2001)]. Each line has been obtained using the reference driving variables presented in Fig. 9, but with changed $T_{0}$ or $h_{a}$ values. (a) Effect of changes in $T_{0}\left(+1^{\circ},+3^{\circ},+5^{\circ}\right.$ and $\left.-1^{\circ},-3^{\circ},-5^{\circ} \mathrm{C}\right)$, (b) effect of changes in $h_{a}(+0.05,+0.10$, and $-0.05,-0.10)$. The arrows denote different scenarios (e.g., a change in $\theta_{0}$ with a concurrent change in $h_{a}$ ).

(e.g., the difference between $\theta_{0}$ and $\theta$ at $0.025 \mathrm{~m}$ depth for our olive grove was $\sim 0.15 \mathrm{~m}^{3} \mathrm{~m}^{-3}$ ). From typical water retention curves for clay we estimated that daytime $\theta_{0}$ for K01 would have ranged roughly between 0.005 and $0.10 \mathrm{~m}^{3} \mathrm{~m}^{-3}$.

We assumed that the clay type at the Antissa site is predominantly montmorrilonite (i.e., $A_{c}=0.3$; see Ten Berge 1990), because when using $A_{c} \leq 0.1$, tests using Eqs. (2)-(9) showed that these high values of adsorption are theoretically not possible. Using Eq. 7, with $\phi_{c}=0.168, \theta_{30}$ is calculated to be $0.134 \mathrm{~m}^{3} \mathrm{~m}^{-3}$. This means that $\theta_{0}<\theta_{30}$ during most of the time; that is, adsorption could have taken place provided the other key conditions $\left(T_{0}\right.$ and $\left.h_{a}\right)$ were right.

Figures 13 and 14 show the effect of a change in $\theta_{0}$ on the amount of vapor adsorbed by a soil with $A_{c}=0.3$ 


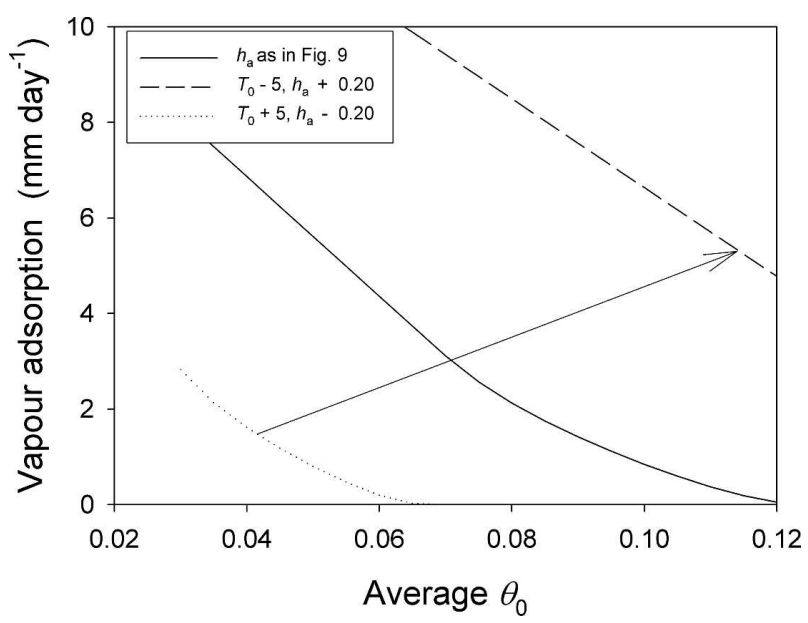

FIG. 14. Vapor adsorption as a function of $\theta_{0}$, calculated using Eqs. (2)-(4) and Eqs. (7)-(9), with $A_{c}=0.3$ and $\phi_{c}=0.168$ in Eq. (7). The solid line has been obtained using the reference driving variables presented in Fig. 9, the other two with perturbed values of $T_{0}$ and $h_{a}$.

and $\phi_{c}=0.168$, during a $24-\mathrm{h}$ interval. These data were obtained with Eqs. (2)-(4) and Eqs. (7)-(9) using the driving variables in Fig. 9 (with $\theta_{0}, T_{0}$, and $h_{a}$ stepwise increased/decreased to create the curves). The assumption is that the shape of the diurnal course of $T_{0}, h_{a}$, etc. in this figure is approximately comparable to the Mediterranean conditions measured by K01.

First, Figs. 13 and 14 show that the high adsorption values recorded by K01 are theoretically possible. This can also be proved using Eq. (1), with a value for $S$ of about $5 \mathrm{~mm}$ day $^{-0.5}$ (adsorption would only take place during at most about $8 \mathrm{~h}$ each day, so $t=0.33$ day). D. A. Rose (1968) found maximum values of $S$ of $3.61 \mathrm{~mm}$ day $^{-0.5}$ for sepiolite and of $1.15 \mathrm{~mm} \mathrm{day}^{-0.5}$ for various soils. However, the high clay content found at the locations studied by K01 may explain the relatively large sorptivity.

Second, Fig. 13 shows that an increase in $\theta_{0}$ would lead to a decrease in $E^{-}$(and therefore contradict K01's Fig. 9), but only if $T_{0}$ and $h_{a}$ are kept constant (the curves plotted in Figs. 13 and 14; see, e.g., scenario 1 in Fig. 13a). With a concurrent drop in $T_{0}$ (because of the moister surface conditions, e.g., scenario 2 in Fig. 13a), $E^{-}$would stay roughly the same or go up slightly.

However, the decrease in $T_{0}$, as $\theta_{0}$ increases, would also have been accompanied by an increase in $h_{a}$ (generally, more humid atmospheric conditions prevail when $\theta$ is high), which would have caused $E^{-}$to increase (e.g., scenario 2 in Fig. 13b). Combinations of the two effects (decrease in $T_{0}$ and increase in $h_{a}$ ) will almost certainly cause $E^{-}$to rise when $\theta_{0}$ increases (Fig.
14). Figures 13 and 14 corroborate the results found by K01. However, we cannot rule out that a temperature effect on the TDR sensors, employed by K01 to calculate adsorption, exaggerated the values of adsorption (see Verhoef et al. 2006), despite the fact that K01 attempted to filter out this spurious oscillation.

With the help of these figures we can also explain why K01 report that vapor adsorption decreases with increasing minimum values of $h_{a}$ (and hence increasing values of $e_{a}$ ). Scenario 4 in Fig. 13b shows that this is theoretically possible, because at the same time $\theta_{0}$ would have increased.

Also, it appeared that adsorption at the Antissa site was influenced by the amount of vegetation cover: lowest values of adsorption were found for the subplot that was fully covered with shrubs (on average about 0.27 mm day ${ }^{-1}$ over the period between early April and end of June). Highest amounts of adsorption were found for a bare plot at this site (on average $\sim 1.2 \mathrm{~mm} \mathrm{day}^{-1}$ ). Plots covered with natural vegetation had intermediate values. These findings are clearly related to the amount of radiation received by the soil (less for a densely vegetated plot), and the related $\theta_{0}$ and $T_{0}$ (see section 3 ). This corresponds to the results presented for the olive grove: the OLS (generally receiving higher radiation) exhibited higher vapor adsorption than the ILS.

Finally, K01 found adsorption to decrease with increasing clay content. This finding seems to contradict Eq. (7) (higher clay content results in a larger $\theta_{30}$ values, and hence an increased probability of adsorption). However, K01 also reported that higher $\phi_{c}$ values were related to lower values of macroporosity. D. A. Rose (1968) states that the net effect of porosity on sorptivity is obscure. He goes on to say: "An increase in porosity will cause an increase in vapour diffusivity and an increase in vapour sorptivity. There will, however, be fewer contacts between aggregates and less continuity of liquid films, leading to a decreased liquid diffusivity and sorptivity."

\section{Conclusions}

Diurnal and daily rates of vapor adsorption for a sandy loam soil in the vicinity of a mature olive tree were measured using eight lysimeters, at distances of 1 and $2 \mathrm{~m}$, respectively, from the tree trunk, at the four principal compass directions. The bulk of the adsorption occurred between midafternoon and early evening, because during this period $\theta_{0}$, and hence $e_{s, 0}$ was lowest, in combination with relatively high values of $e_{a}$, as a result of afternoon winds bringing in relatively moist air from the sea. The lysimeters that were furthest away from the tree trunk exhibited the largest values of va- 
por adsorption, because their surface soil moisture content, $\theta_{0}$, was slightly lower (as a result of higher solar radiation, their daytime evaporation was larger, causing $\theta_{0}$ to fall more). The olive trees not only provide shading (from solar radiation), but they also limit the sky view factor, thus increasing longwave incoming radiation. This radiation term was not measured directly, but it may also have affected variations in $T_{0}$ and $\theta_{0}$.

We conclude that only the combination of Eqs. (2)(9) [ideally with Eqs. (7) and (8) to describe the relation between $\theta$ and $h_{\mathrm{s}}$, rather than Eqs. (5) and (6), which involves the van Genuchten equation extrapolated beyond values for which $\Psi-\theta$ data are generally available) captures the interplay between surface and atmospheric variables in the process of vapor adsorption properly. Empirical equations (see e.g., Agam and Berliner 2004; Kosmas et al. 1998), may lead to inaccurate estimates when used for a site or season different from the one for which the equation parameters were derived.

Therefore, reliable prediction of vapor adsorption requires continuous measurements of atmospheric variables, and surface variables $\theta_{0}$ and $T_{0}$. Because of problems related to direct monitoring of $\theta_{0}$ (as explained in the introduction) it may be preferred to sample $\theta_{0}$ gravimetrically, during morning and late afternoon, after which a diurnal curve can be fitted (representing the course shown in Fig. 7; see also Agam and Berliner 2004); $T_{0}$ can be measured continuously using an infrared thermometer (IRT) connected to a datalogger. Alternatively, $T_{0}$ can be measured manually on several occasions, using a handheld IRT, and a cosine-type equation fitted; $T_{0}$ is an important variable in the adsorption process, yet it is generally ignored (apart from using it to distinguish between dew formation and vapor adsorption; see Agam and Berliner 2006). The intricate link between $\theta_{0}, T_{0}$, and adsorption, combined with the dependence of emissivity on $\theta_{0}$, has considerable implications for remote sensing of soil moisture (e.g., via estimates of thermal inertia) and surface temperature in arid and semiarid regions.

Acknowledgments. The experiment used equipment funded by Natural Environment Research Council (NERC) grants (NER/M/S/2000/00268 and NER/T/S/ 1999/00108). This research was supported by a Marie Curie European Reintegration Grant within the Sixth European Community RTD Framework Programme, MERG-CT-2004-510524. We thank Bruce Main for supplying the Campbell datalogger program and Ignacio Girón and José Rodriguez for their help in the field. Furthermore, we thank David Thornley for determining the adsorption isotherm for the Coria soil. Finally, we are grateful for the valuable comments supplied by
Dr. Derek Rose on a draft version of this manuscript and the suggestions made by Dr. Francisco Domingo.

\section{REFERENCES}

Agam, N., and P. R. Berliner, 2004: Diurnal water content changes in the bare soil of a coastal desert. J. Hydrometeor., 5, 922-933.

— , and — 2006: Dew formation and water vapour adsorption in semi-arid environments-A review. J. Arid Environ., $\mathbf{6 5}, 572-590$.

Cary, J. W., R. A. Kohl, and S. A. Taylor, 1964: Water adsorption by dry soil and its thermodynamic functions. Soil Soc. Amer. Proc., 28, 309-313.

Diaz-Espejo, A., A. Verhoef, and R. Knight, 2005: Illustration of micro-scale advection using grid-pattern mini-lysimeters. $A g$ ric. For. Meteor., 129, 39-52.

Domingo, F., L. Villagarcia, A. J. Brenner, and J. Puiddefabregas, 1999: Evapotranspiration model for semi-arid shrublands tested against data from SE Spain. Agric. For. Meteor., 95, 67-84.

Jacobs, A. F. M., A. Van Pul, and R. M. El-Kilani, 1994: Dew formation and the drying process within a maize canopy. Bound.-Layer Meteor., 69, 367-378.

—_ B. G. Heusinkveld, and S. M. Berkowicz, 1999: Dew deposition and drying in a desert system: A simple simulation model. J. Arid Environ., 42, 211-222.

Kosmas, C., N. G. Danalatos, J. Poesen, and B. Van Wesemael, 1998: The effect of water vapour adsorption on soil water content under Mediterreanean climatic conditions. Agric. Water Manage., 36, 157-168.

— M. Marathianou, S. Gerontidis, V. Detsis, M. Tsara, and J. Poesen, 2001: Parameters affecting water vapour adsorption by the soil under semi-arid climatic conditions. Agric. Water Manage., 48, 61-78.

McInnes, K. J., J. L. Heilman, and M. J. Savage, 1994: Aerodynamic conductances along a bare ridge-furrow tilled soil surface. Agric. For. Meteor., 68, 119-131.

Milly, P. C. D., 1984: A simulation analysis of thermal effects on evaporation from soil. Water Resour. Res., 20, 1087-1098.

Monteith, J. L., 1957: Dew. Quart. J. Roy. Meteor., 83, 322-341.

Murray, F. W., 1967: On the computation of saturation vapor pressure. J. Appl. Meteor., 6, 203-204.

Nakayama, F. S., R. D. Jackson, B. A. Kimball, and R. J. Reginato, 1973: Diurnal soil-water evaporation: Chloride movement and accumulation near the soil surface. Soil Sci. Soc. Amer. Proc., 37, 509-513.

Ninari, N., and P. R. Berliner, 2002: The role of dew in the water and heat balance of bare loess in the Negev desert: Quantifying the actual dew depositions on the soil surface. Atmos. Res., 64, 323-334.

Orchiston, H. D., 1954: Adsorption of water vapour: 1. Soils at $25^{\circ}$ C. Soil Sci., 76, 453-465.

Philip, J. R., 1957: The theory of infiltration. 4. Sorptivity and algebraic infiltration equations. Soil Sci., 84, 257-264.

Rose, C. W., 1968: Water transport in soil with a daily temperature wave. I. Theory and experiment. Aust. J. Soil Res., 6, $31-44$.

Rose, D. A., 1968: Water movement in dry soils. I. Physical factors affecting sorption of water by dry soil. J. Soil Sci., 19, 81-93. 
_ - 1996: The dynamics of soil water following single surface wettings. Eur. J. Soil Sci., 47, 21-31.

Scanlon, B. R., and P. C. D. Milly, 1994: Water and heat fluxes in desert soils. 2. Numerical simulations. Water Resour. Res., 30, 721-733.

Ten Berge, H. F. M., 1990. Heat and Water Transfer in Bare Topsoil and the Lower Atmosphere. Simulation Monogr., No. 33, Pudoc, 207 pp.

van Genuchten, M. T., 1980: A closed-form equation for predict- ing the hydraulic conductivity of unsaturated soils. Soil Sci. Soc. Amer. J., 44, 892-898.

Verhoef, A., 2004: Remote estimation of thermal inertia and soil heat flux for bare soil. Agric. For. Meteor., 123, 221-236.

_, J. Fernandez-Galvez, A. Diaz-Espejo, B. E. Main, and M. El-Bishti, 2006: The diurnal course of soil moisture as measured by various dielectric sensors: Effects of soil temperature and the implications for evaporation estimates. J. Hydrol., 321, 147-162. 